\title{
Medicine and Religion
}

\section{Lectures on heaven: an excursion into the playground of the theologians}

\author{
A T GROUNDS
}

\begin{abstract}
"The British churchman," Ronald Blythe once remarked, "goes to church as he goes to the bathroom, with the minimum of fuss and no explanation if he can help it." I can understand such reticence: in $1974 \mathrm{I}$ spent a year away from my medical school studying theology, a distinctively unfashionable subject. My academic credentials for this enterprise were not encouraging; at school my only venture into the subject had resulted in failing scripture "O" level-twice. (I decided to omit that from my application form and, fortunately, my interviewer was an optimistic man. "The year isn't too demanding," he said, "and no one ever fails it.") The course was an introductory one, arranged by the divinity school at Cambridge for graduates in other subjects. It was taken mainly by ordinands, whose quiet respectfulness and concern to preserve their beliefs irritated me considerably. My prejudices and misgivings were further enhanced at the outset by the first invitation for new students to meet the staff of the department. Whereas in all other faculties such informal introductions would be over coffee or, if you were fortunate, sherry, the divinity school, true to stereotype, invited us for afternoon "tea and biscuits."
\end{abstract}

\section{Psychiatrists and theologians}

The place occupied by theologians in universities is similar to that occupied by psychiatrists in medicine. Both evoke responses of perplexity or sarcastic joking from their academic colleagues, but both find their disciplines uniquely fascinating because they deal with the most fundamental questions. And both psychiatrists and theologians are faced with the problem of convincing others of the value of what they do. In this respect the theologians have by far the more difficult task. To most people religious questions are not even controversial any more, but simply irrelevant. Religious practice is vestigial and confined to dutiful attendance at brief rituals marking the major family events of birth, marriage, and death. This state of affairs has been aptly summarised in Alasdair MacIntyre's observation that, "The creed of the English is that there is no God and it is wise to pray to him from time to time."

The range of interests and attitudes amongst theologians is wide. Most stand within a church tradition that they seek to interpret and make intelligible. Some are specialist historians and some textual scholars. A few engage in systematic theology -that is, the formal elaboration and interpretation of doctrine, as contained in the creeds-and some are philosophers, who spend their time worrying about what it all means. Some are conservative in their beliefs, others radical. (In the 1960s there

Bethlem Royal and Maudsley Hospitals, Denmark Hill, London SE5 8AZ

A T GROUNDS, BMEDSCI, BM, registrar in psychiatry was even a phase of "death of God" theology, but, appropriately, we do not hear about that any more.) A few, of course, are extremely eccentric.

One of the most memorable professors (now retired) always lectured on the top floor of the divinity school, in a cold and gloomy room with a high vaulted ceiling and furnished with benches and a lectern, like a huge, neglected Victorian mission hall. He invariably started late. At twenty minutes past the scheduled hour we would hear him coming slowly up the stone stairs. On arrival, he would slam the door and walk down the aisle, scowling, his gown falling off his shoulders, and under one arm a pile of books that he would throw down on the desk and rarely refer to again. His Scottish accent rumbling and echoing round the room rendered his words indistinct, and there were long periods of silence in which he would stare out of the window or pace up and down like a distracted exam invigilator. He did not so much lecture as ponder aloud over questions of immense difficulty, with ferocious expressions on his face and a manner of agonised intensity. But there were unpredictable moments of humour, as on one occasion when he suddenly glared at someone busily writing notes, and recalled how Gilbert Ryle used to threaten, "if I see you writing down every word I say, I'll throw you out, since I'll know you aren't listening!' But behind such eccentric behaviour was an extraordinary commitment to his subject. He was constantly exploring, grappling with issues rather than reaching conclusions, and drawing from politics, history, and literature to illuminate the complexity and depth of theological questions. While rejecting as inadequate "fashionable sorts of subjectivism," he was also awed by the profound difficulties of validating theological assertions. In the preface to a recent collection of papers he said that if they had any lesson to teach it was "that of the many-sidedness involved in serious theological work. There are many escape routes proposed for the avoidance of this discipline." He gave me a glimpse of what theology is properly about, and confirmed my view that those who express glib certainties (one way or the other) about religion are always taking such escape routes and have not begun to understand the nature of the problem.

\section{A totally different world}

On entering theology from a scientific background, my first impression was of a totally different world. Having been used to a discipline in which theories were closely associated with hard evidence, I found that in theology the links between theory and evidence seemed either non-existent or extremely tenuous: a little sceptical questioning from an empiricist or logician and huge, fragile edifices of theological construction would apparently fall down. It is a pleasing game to play and was successfully tried in the 1950s by philosophers influenced by the tenets of logical positivism, who sought to dismiss religious language as vacuous. The game works only, however, if it is assumed that 
theological assertions are literal propositional descriptions of God or the world. The debate merely illustrated that this assumption is wrong; but the controversy was valuable in stimulating much subsequent work that attempted to clarify further the nature of religious language and how it functions.

It is self-evident that our limited conceptual apparatus is a poor vehicle for trying to express the inexpressable. By definition, any transcendent reality eludes conceptual articulation, and religious language has to borrow the words and images of ordinary human experience to try and talk of what transcends it. It is only to be expected that this puts the language under strain and leads to anthropomorphism, paradox, and contradiction. But this is not a new observation. The problem was well understood by the mediaeval School-men, who knew that it is easier to say what God is not than what he is, and warned that anthropomorphism is a greater error than saying nothing at all. This difficulty helps to explain why theological language may appear rather absurd at first sight. When I began the course I looked through essay questions set in previous examination papers on Christian doctrine and was faced with examples such as the following: Is God a god? What dangers are there in thinking of the Trinity as a society of persons ? Can God love all yet choose some ? How much does God know about the world. Can he enter into the experience of sin and suffering without ceasing to be divinely perfect? Is heaven a democracy? Such questions are very perplexing and, at first, one wonders what possible criteria there could be for deciding them-if they have any meaning, that is.

After a time, however, I began to reconsider the sharp distinction between science and theology with which I had begun. I developed a respect for how theologians reason, and became aware that science was not quite as objective or religion as subjective as I had assumed. In particular, I recognised that the conception of science I had imbibed as a student was naive and untenable. The empiricist view of science has been severely criticised during the past 30 years. The view contains three claims: firstly, that science starts from publicly observable data, which may be described in a language independent of theoretical assumptions; secondly, that theories are supported or falsified by comparison with these experimental data; and, thirdly, that the choice between theories is objective, rational, and in accordance with specifiable criteria. It has become increasingly clear that this view will not do. In practice, firstly, the distinction between theory and observation is blurred-the theories we hold influence our observations. Secondly, scientific theories are usually underdetermined by the facts, and discordant data are not sufficient to lead to their rejection. Thirdly, considerations other than empirical are used to choose between rival theories. For example, a theory may be preferred on the basis of an aesthetic criterion, such as its mathematical simplicity. Furthermore, scientific descriptions employ models. These cannot be regarded as literal representations of the world, but, at best, are provisional, humanly created ways of imagining what is not directly observable. They are symbolic representations of aspects of the world not directly accessible to us. Scientific activity is also dependent on paradigms-traditions passed on through exemplary pieces of past work.

In the light of considerations such as these, theology, as a subject of human inquiry, does not appear quite so different. Both scientists and theologians work within a historical tradition that shapes their activities; both use theories that are underdetermined by facts, and theoretical models, whose relationship to what they describe is uncertain and problematical.

\section{More mystery than certainty}

But there remains one important difference between the two disciplines. Whereas most of us are fairly confident that scientific language does refer to something real, the question of whether theological language refers to anything at all (apart, that is, from our neurotic traits) is much more uncertain. I suspect that it may be impossible in principle to know; but in studying theology I found that my impatience and exasperation with the verbal formulations of belief were balanced with an awareness that the words could also convey glimpses of profound insight into human experience. Often, this occurs more effectively in the forms of liturgy or of poetry-for example, T S Eliot's Four Quartets or R S Thomas's collection, Laboratories of the Spirit-than in textbooks of systematic theology. But religious insights are more than just aesthetic or nostalgic feelings wrongly labelled: they also specify a certain perspective on the world and provide symbols that can illuminate and interpret history and experience. Our descriptions would be more shallow and less searching without them. William James, at the end of his book The Varieties of Religious Experience, correctly located the essential concern of theology when he concluded that: "However particular questions about our individual destinies may be answered, [to] acknowledge them as genuine questions, and to live in the sphere of thought which they open up . . . is to be religious." Religion has much more to do with inquiry and mystery than with sects and certainty.

What is the relation of all this to the discipline in which I work - psychiatry? Certainly, religious belief can be an intriguing and often revealing expression of psychopathology, but the relationship may be two way. Those believers I have met who have become mentally ill with symptoms of prominent religious content generally seem to be fundamentally mistaken in their theology as well. There is something reassuring about that. But such connections between psychiatry and religion are superficial. Essentially, the two subjects are concerned with quite different categories of questions, which should be carefully distinguished and should probably maintain a respectful distance from each other. Theology is intrinsically interesting; one of the recurrent jokes in the subject tells the story of the professor of theology who died, and on the Day of Judgment he saw two doors in front of him, one labelled "Heaven" and the other labelled "Lecture on Heaven." He went through the second out of sheer habit. I would probably do the same, not out of habit but curiosity, and to meet some old friends.

(Accepted 19 May 1981)

ONE HUNDRED YEARS AGO SIR,-Dr Coleman's letter in your issue of the 22nd, asking if the foot-and-mouth disease, now occurring in various parts of the country, is coincident with outbreaks of diphtheria, will probably elicit two or three affirmative replies. Should this be the case, you will, perhaps, permit me to warn your readers against attaching too much importance to mere coincidence. If there is anything certain in connection with so obscure a subject as the communicability of animal diseases to man, it is that epizootic aphtha is a specific disease, having a specific contagium, and that it communicates itself. In the earliest recorded outbreaks of the disease, it was noted that it spread to human beings, and since 1834 the disease has been repeatedly observed in children and others, especially raw milk-feeders-a fact readily accounted for when it is remembered that vesicles often form upon the teats, and are ruptured in milking.

"The communication of the [foot-and-mouth] disease to man admits of no doubt," says Gamgee. "The history of the various outbreaks of the disease demonstrates this. There have been many contradictory statements on the matter, but the symptoms repeatedly noticed in man after drinking the milk of diseased cows are unmistakable." Descriptions of these may be found in the Veterinarian for 1841 .

A specific disease can only communicate itself, or a malady so closely allied as to be regarded as a modified form of it. Now it appears to me contrary to all we know of diphtheria, to hold that it is even remotely related to the epizootic.

I am happy to say that we have had no cases of foot-and-mouth disease in Birkenhead or the neighbourhood lately. But in the first quarter of 1876 , when it was prevalent, two or three cases of the disease in the human subject were brought under my notice. Oddly enough, at this time, the mortality ascribed to diphtheria was a little higher than usual.-I am, sir, yours, etc, FrancIS VACHER. (British Medical fournal, 1881.) 